\title{
The influence of prolapse surgery on sexual activity of
}

\section{women}

\author{
Linde T. van Genugten, Paul J. Q. van der Linden
}

Department of Gynaecology and Obstetrics, Deventer Hospital, Deventer, The Netherlands

Email: lindevangenugten@hotmail.com, p.j.q.vanderlinden@dz.nl

Received 12 January 2014; revised 10 February 2014; accepted 17 February 2014

Copyright @ 2014 Linde T. van Genugten, Paul J. Q. van der Linden. This is an open access article distributed under the Creative Commons Attribution License, which permits unrestricted use, distribution, and reproduction in any medium, provided the original work is properly cited. In accordance of the Creative Commons Attribution License all Copyrights (C) 2014 are reserved for SCIRP and the owner of the intellectual property Linde T. van Genugten, Paul J. Q. van der Linden. All Copyright (C) 2014 are guarded by law and by SCIRP as a guardian.

\section{ABSTRACT}

Aims: A prospective study to assess sexual activity in patients with pelvic organ prolapse (POP) and evaluate changes in sexual functioning after surgery. Secondary outcomes were quality of life and anatomical results. Methods: Patients completed the validated Leiden Questionnaire (LQ) and the short form 36 (SF-36) pre- and two months postoperatively. SPSS 19.0 was used for statistical analysis. Results: 74 patients (average age 61.5 years) were approached, of whom $33.8 \%$ were sexually inactive due to other reasons than POP. 23 patients (average age 56.7 years) were included for further analysis. Postoperatively we found a significant improvement for orgasm during intercourse. The remaining domains didn't change significantly. A trend is noted, indicating that sexual activity stayed unchanged in $82.6 \%$ of patients. Dyspareunia improved in $47.8 \%$ of patients, lubrication in $34.8 \%$ and sexual satisfaction in $\mathbf{4 0 \%}$. Quality of life improved in $\mathbf{7 3 . 9 \%}$. We found a significant improvement in POP grading. Conclusion: More than a third of the patients presenting with POP are not sexually active due to other reasons than POP. POP surgery appears to improve lubrication, dyspareunia, sexual satisfaction and orgasm during intercourse in a considerable part of patients. Furthermore, there's no negative influence on sexual activity. POP surgery improves quality of life in the majority of patients.

\section{KEYWORDS}

Sexual Activity; Sexual Functioning; Pelvic Organ Prolapse; Surgery; Leiden Questionnaire

\section{INTRODUCTION}

The prevalence of pelvic organ prolapse (POP) increases with age, to $41 \%$ - $75 \%$ in women over 50 years of age, who have given birth vaginally [1,2]. Sexual dysfunction is reported in up to $68 \%$ of patients preoperatively, mainly concerning problems regarding lubrication, dyspareunia and satisfaction [3-5]. This might be influenced by both functional and psychological consequences of POP $[3,4,6,7]$. Although sexual dysfunction seems to be related to $\mathrm{POP}$, it appears to be independent of the grading or localization $[4,6,7]$.

Research on the influence of POP surgery on the sexual functioning shows conflicting results. Results range from improvement, [3,7-14] to unchanged, [15-17] and deterioration of sexual functioning postoperatively [3, 18-22].

Surgery is often considered successful when a significant anatomical improvement is reached. Patient satisfaction however, correlates strongly with self-described goals, such as the resumption of daily activities (40.2\%) and symptom reduction (38.1\%) [23]. So symptom reduction, including sexual dysfunctioning, is an important outcome measure for patients.

\section{Aims}

Our study will focus on sexual activity in women with POP and the assessment of different domains of sexual functioning after POP surgery. Secondary outcomes are quality of life and anatomical results. To this end, we carried out a prospective study, with a follow-up time of 2 months.

\section{METHODS}

A prospective study was carried out between January 2012 and October 2012 in Deventer Hospital, Deventer, The Netherlands. Deventer Hospital is a secondary-level teaching hospital. Oral and written informed consent was 
obtained from all participants.

Women with POP scheduled for surgical correction, were eligible for participation. Sexual activity was assessed in all women. Concerning the influence of POP surgery, we included women who where sexually active, defined as have had coitus in the month prior to surgery. Women who where not sexually active due to POP were also included. Sexually inactive women, due to other than POP related causes, were excluded. Other exclusion criteria were concomitant incontinence surgery, postoperative use of local estrogens and inadequate composure of the Dutch language. All patients were gynaecologically examined before and 6 weeks after surgery and POP staging was performed using the Baden and Walker classification system.

The primary outcome measure was sexual functioning, divided into different domains. To this end we used the Leiden Questionnaire (LQ), a validated Dutch questionnaire [24]. The LQ comprises ten questions concerning sexual functioning, addressing sexual activity, frequency of sexual contact, sexual desire, lubrication, orgasm during intercourse and masturbation, dyspareunia and sexual satisfaction. Answers are according to a 5-point Likert scale, ranging from never to always. The higher the score, the higher the degree of dysfunction. Patients completed the LQ prior to and 2 months postoperatively.

The secondary outcome quality of life was assessed using the SF-36 questionnaire. Anatomical results were analysed comparing pre- and postoperative POP grading.

Power analysis was not possible, because the LQ was never used for this research question and because of contradicting results in the existing literature so far. For this pilot study we expected a response rate of $50 \%$.

IBM SPSS Statistics 19.0 (Chicago, Illinois, USA) was used for statistical analysis. The Shapiro-Wilk test was used to assess whether the variables were normally distributed, using a statistics $W$-value of $\geq 0.9$ as a cut-off point. The LQ was recoded into a uniform five-point Likert scale. Data were analysed using the non-parametric Wilcoxon signed rank test. If no significant difference was found, a post hoc power analysis was performed using $\mathrm{G}^{*}$ power 3.1. Given the high percentage of excluded and declining patients, baseline characteristics of these groups were compared with the patients included. We used the Mann-Whitney $U$-test for data with a skewed distribution and the Fishers exact test and the Chi-square for the categorical, binary variables. A p-value of $<0.05$ was considered significant.

\section{RESULTS}

74 patients (average age 61.5 years) were approached. Preoperatively 25 out of 74 patients (33.8\%) were sexually inactive due to other reasons than POP. Two patients were not sexually active due to POP. Table 1 shows sexual activity of all patients and the reason for being sexually inactive, when known. 39 patients were found eligible for further analysis. Thereof 16 patients declined participation. 23 patients (average age 56.7 years) were included. Details are shown in Figure 1.

Table 1. Sexual activity preoperative.

\begin{tabular}{lc}
\hline \multicolumn{1}{c}{ Sexual activity } & N (\%) \\
\hline Sexually active & $47(63.5 \%)$ \\
Not sexually active due to POP & $2(2.7 \%)$ \\
Not sexually active & $25(33.8 \%)$ \\
Widow & $13(17.6 \%)$ \\
Male factor & $4(5.4 \%)$ \\
No sexual desire & $2(2.7 \%)$ \\
Other physical problems & $2(2.7 \%)$ \\
No partner & $1(1.3 \%)$ \\
Unknown & $3(4.1 \%)$ \\
\hline
\end{tabular}

Note: $\mathrm{N}=$ number of patients; $\%$ = percentage of 74 patients.

Patients undergoing POP surgery 74 (100\%)

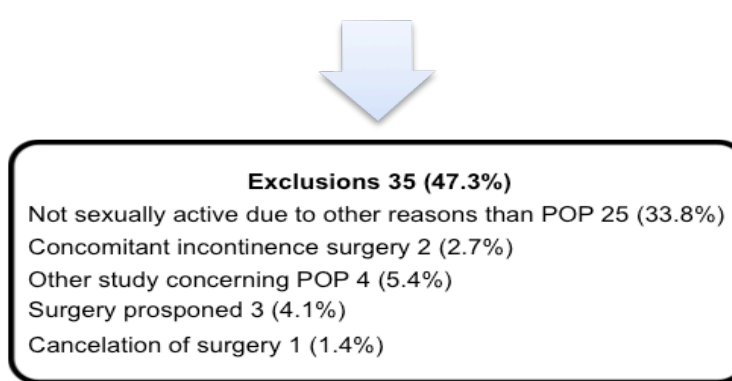

Patients eligible for inclusion 39 (52.7\%)

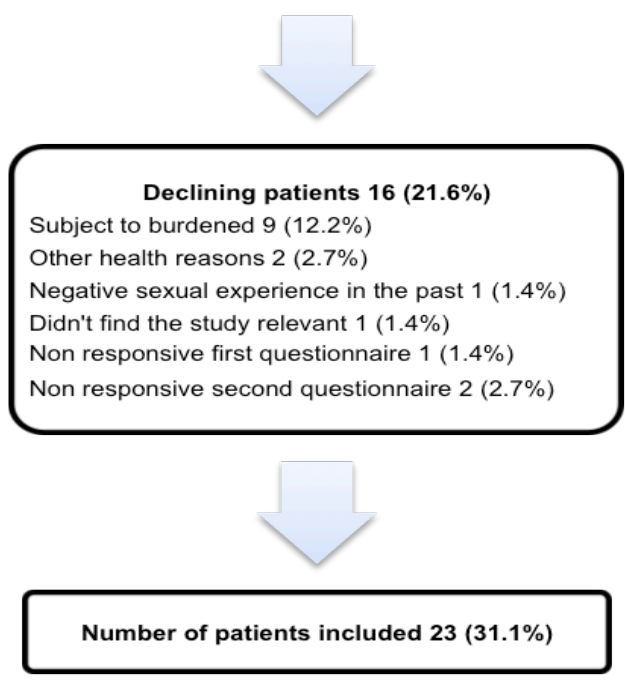

Figure 1. Flowchart in- and exclusions. 
The patient characteristics are shown in Table 2. The average age was $56.7 \pm 8.4$ years. Four patients had already undergone a hysterectomy, one in the context of POP. The latter was also the only patient with a recurrence POP. The average follow-up time was $10.3 \pm 1.9$ weeks (range 8.0 - 15.1 weeks).

Table 3 shows the different surgical procedures carried out. Most patients underwent a combination of procedures. There were five complications postoperatively: one hematoma on the posterior wall, two urinary tract infections and one postoperative bleeding, for which surgical exploration in theatre. One patient suffered from severe, possibly neuropathic pains at the side of operation.

Table 2. Demographic features.

\begin{tabular}{|c|c|c|c|}
\hline Variable & Outcome & SD & Range \\
\hline Age (in years) ${ }^{* *}$ & 56.7 & \pm 8.43 & $35-70$ \\
\hline $\begin{array}{l}\text { Marital status }^{*} \\
\text { Relationship } \\
\text { Divorced }\end{array}$ & $\begin{array}{c}22(95.7 \%) \\
1(4.3 \%)\end{array}$ & & \\
\hline Male partner ${ }^{*}$ & $23(100 \%)$ & & \\
\hline $\begin{array}{l}\text { Total parity }(\mathrm{CS}+\text { vaginal })^{* * a} \\
\text { Vaginal parity }^{* * a}\end{array}$ & $\begin{array}{l}2.0 \\
2.0\end{array}$ & $\begin{array}{l} \pm 0.89 \\
\pm 0.81\end{array}$ & $\begin{array}{l}1-5 \\
1-4\end{array}$ \\
\hline $\begin{array}{l}\text { Ethnicity } \\
\text { White }\end{array}$ & 23 (100\%) & & \\
\hline $\begin{array}{l}\text { BMI }\left(\mathrm{kg} / \mathrm{m}^{2}\right)^{* * a} \\
\quad \text { Overweight }\left(\mathrm{BMI} \geq 25 \mathrm{~kg} / \mathrm{m}^{2}\right)^{*} \\
\text { Obese }\left(\mathrm{BMI} \geq 30 \mathrm{~kg} / \mathrm{m}^{2}\right)^{*}\end{array}$ & $\begin{array}{c}26.08 \\
8(34.8 \%) \\
4(17.4 \%)\end{array}$ & \pm 4.3 & $19.2-39$ \\
\hline $\begin{array}{l}\text { Menopausal status* } \\
\text { Postmenopausal } \\
\text { Pre- or perimenopausal }\end{array}$ & $\begin{array}{c}17(73.9 \%) \\
6(26.1 \%)\end{array}$ & & \\
\hline Prior hysterectomy ${ }^{*}$ & $4(17.4 \%)$ & & \\
\hline Prior POP surgery ${ }^{*}$ & $1(4.3 \%)$ & & \\
\hline $\begin{array}{l}\text { Smoking } \\
\quad \geq 10 \text { cigarettes/day }\end{array}$ & $\begin{array}{c}5(21.7 \%) \\
3(13 \%)\end{array}$ & & \\
\hline
\end{tabular}

Note: Normal distribution of continuous variables was tested using the Shapiro Wilk test. Abbreviations: CS = caesarean section; $\mathrm{BMI}=$ Body Mass Index; SD = standard deviation. ${ }^{*}$ Categorical variables, represented as number $(\mathrm{N})$ and percentages (\%). ${ }^{* *}$ Normally distributed continuous variable. Mean \pm SD and the range. ${ }^{* *}$ a Skewed continuous variables. Median \pm $\mathrm{SD}$ and the range.

Table 3. Procedures.

\begin{tabular}{ll}
\hline Type of operation & N (\%) \\
\hline Anterior colporrhaphy & $19(76 \%)$ \\
Posterior colporrhaphy & $10(40 \%)$ \\
Manchester Fothergill & $9(36 \%)$ \\
Vaginal hysterectomy & $7(28 \%)$ \\
\hline
\end{tabular}

Note: Categorical variables, represented as number $(\mathrm{N})$ and percentages (\%). 17 patients (68\%) underwent a combination of procedures.
Postoperatively there was a significant improvement $(p=0.008)$ of orgasm during intercourse. No significant differences were found for the other domains, as stated in Table 4. Post hoc power analysis showed a power of $<0.8$. Table 5 shows trends postoperatively. Two preoperative sexually active patients were not sexually active at follow-up. In one patient this was related to severe, possibly neuropathic pains. In the second patient it was related to pain due to the sutures and increased vaginal discharge. The two patients who were not sexually active preoperatively, were both sexually active postoperative. Five patients (21.7\%) denoted a deterioration of dyspareunia, of which 3 patients had de novo dyspareunia.

As for quality of life, a significant improvement ( $\mathrm{p}=$ 0.035 ) was seen on the domain "changes in health" and a significant deterioration ( $p=0.012$ ) was seen on the domain "physical role functioning". The total score and the other domains didn't show significant differences. Looking at trends 17 patients (73.9\%) showed an improvement in the total score. The Wilcoxon signed rank test showed a significant improvement of cystocele ( $\mathrm{p} \leq$ $0.001)$, rectocele $(\mathrm{p}=0.005)$ and descensus uteri $(\mathrm{p} \leq$ 0.001).

Comparing the excluded and declining patients with the patients included, no significant differences were found in POP grading and surgical procedures carried out. The patients included were significantly more often sexually active ( $\mathrm{p} \leq 0.001)$, had a partner more often ( $\mathrm{p} \leq$ $0.001)$ and were younger $(p=0.02)$. As for post-

Table 4. LQ scores preoperative and two months postoperative.

\begin{tabular}{lccc}
\hline \multicolumn{1}{c}{ Domain } & Pre-operative & Post-operative & p-value \\
\hline Sexual activity (1) & $0.91 \pm 0.29$ & $0.91 \pm 0.29$ & 1.000 \\
$\begin{array}{l}\text { Frequency of sexual } \\
\text { contact (5) }\end{array}$ & $2.74 \pm 1.32$ & $2.35 \pm 1.27$ & 0.307 \\
Sexual desire (2) & $3.00 \pm 0.52$ & $3.13 \pm 0.55$ & 0.366 \\
$\begin{array}{l}\text { Lubrication (3) } \\
\text { Dry vagina during } \\
\text { intercourse (7) }\end{array}$ & $2.43 \pm 1.21$ & $2.30 \pm 1.11$ & 0.719 \\
$\begin{array}{l}\text { Orgasm during } \\
\text { masturbation (4) }\end{array}$ & $1.61 \pm 1.59$ & $1.00 \pm 1.24$ & 0.056 \\
$\begin{array}{l}\text { Orgasm during } \\
\text { intercourse (6) }\end{array}$ & $3.00 \pm 0.95$ & $2.35 \pm 1.27$ & $0.008^{*}$ \\
$\begin{array}{l}\text { Feeling of vagina being } \\
\text { to short/narrow (8) }\end{array}$ & $1.74 \pm 1.21$ & $1.35 \pm 1.03$ & 0.175 \\
$\begin{array}{l}\text { Dyspareunia (9) } \\
\text { Sexual satisfaction (13) }\end{array}$ & $2.43 \pm 0.79$ & $2.13 \pm 0.76$ & 0.071 \\
\hline
\end{tabular}

Note: Wilcoxon signed rank test. Between brackets the number of the question of the LQ. Domain scores stated as mean and SD. A lower score indicates improvement. ${ }^{*}$ Significant improvement. 
Table 5. Trends. Changes in domains of sexual functioning.

\begin{tabular}{lccc}
\hline \multicolumn{1}{c}{ Domain } & $\begin{array}{c}\text { Improvement } \\
\text { N (\%) }\end{array}$ & $\begin{array}{c}\text { Unchanged } \\
\text { N (\%) }\end{array}$ & $\begin{array}{c}\text { Deterioration } \\
\text { N (\%) }\end{array}$ \\
\hline Sexual activity & $2(8.7 \%)$ & $19(82.6 \%)$ & $2(8.7 \%)$ \\
$\begin{array}{l}\text { Frequency of sexual } \\
\text { contact }\end{array}$ & $6(26.1 \%)$ & $14(60.9 \%)$ & $3(13.0 \%)$ \\
Sexual desire & $3(13.0 \%)$ & $15(65.2 \%)$ & $5(21.7 \%)$ \\
Lubrication & $8(34.8 \%)$ & $10(43.5 \%)$ & $5(21.7 \%)$ \\
$\begin{array}{l}\text { Dry vagina during } \\
\text { intercourse }\end{array}$ & $11(47.8 \%)$ & $8(34.8 \%)$ & $4(17.4 \%)$ \\
$\begin{array}{l}\text { Orgasm during } \\
\text { masturbation }\end{array}$ & $8(34.8 \%)$ & $13(56.5 \%)$ & $2(8.7 \%)$ \\
$\begin{array}{l}\text { Orgasm during } \\
\text { intercourse }\end{array}$ & $10(43.5 \%)$ & $12(52.2 \%)$ & $1(4.3 \%)$ \\
$\begin{array}{l}\text { Feeling of vagina } \\
\text { being to short/narrow }\end{array}$ & $8(34.8 \%)$ & $11(47.8 \%)$ & $4(17.4 \%)$ \\
Dyspareunia & $11(47.8 \%)$ & $7(30.4 \%)$ & $5(21.7 \%)$ \\
Sexual satisfaction & $9(39.1 \%)$ & $11(47.8 \%)$ & $3(13.0 \%)$ \\
\hline
\end{tabular}

Note: Wilcoxon signed rank test. Changes of the postoperative scores as regards to the preoperative scores.

menopausal status, BMI, parity and recurrence POP surgery there were no significant differences.

\section{DISCUSSION}

\subsection{Main Findings}

The most important finding of our study is that over a third of the patients presenting with POP are not sexually active due to other reasons than POP. Since similar studies haven't taken excluded patients into account, little is known about sexual activity in general in this particular group. One study supports our finding; they found that $38.4 \%$ of women with pelvic floor disorders were not sexually active [25]. Our finding can partly be explained by the fact that over half of the sexually inactive women were widows. Although part of them had a new partner, they didn't have coitus. Probably sexual activity in this age group is less focused on coitus and more on other types of sexual activity and intimacy.

As for the effect of POP surgery on sexual functioning, it didn't affect sexual activity in the majority of patients who were sexually active preoperatively. This is supported by three other studies $[3,16,18]$. On follow-up two patients were not sexually active. In one patient it was related to pain due to the sutures and increased vaginal discharge, so it is to be expected that she will get sexually active again in the long-term after disappearing of these complaints. For the other patient it was related to severe, possibly neuropathic pains. The two patients who were not sexually active preoperatively, were both sexu- ally active at follow-up. This fact is also underexposed in literature. Only one study showed that $21 \%$ of preoperatively sexually inactive patients, resumed sexual activity postoperative. However, the reasons for being sexually inactive are not stated [3]. All other studies excluded women who were sexually inactive, even when this was related to POP.

The significant improvement that we found on the orgasm during intercourse is not endorsed by other studies, that showed no significant difference, $[3,7,15-17]$ or deterioration [9]. There is no clear explanation for this improvement. Looking at trends, the largest improvement was seen in dyspareunia, in nearly half of the patients. Research so far shows miscellaneous results. Six studies support our finding $[3,7,10,11,13,14]$, however, several studies found deterioration [8,19-22]. The latter was particularly associated with implant surgery in the first three months postoperatively. Lubrication, although unchanged in about half of the patients, improved in over a third. This finding is confirmed by a number of studies [3, $7,10,13,14]$. However in four studies that showed improvement in both dyspareunia and lubrication, patients were prescribed local estrogens postoperatively, which may have a positive impact on both domains $[7,10,13,14]$. Three patients had de novo dyspareunia and five patients decreased lubrication. There are several explanations possible. Vaginal nerve innervation and vascularization play an important role in lubrication, by increasing the vaginal blood flow. Theoretically dissection of the vaginal wall may cause damage to the vaginal neurovascularization. There is also a chance of narrowing the supporting tissue surrounding the vagina too much, both proximal and distal $[26,27]$. Finally vaginal surgery can lead to scarring and loss of elasticity of the vaginal wall. A combination of these factors, individually or together, may play a role in decrease in lubrication and increase dyspareunia.

Preoperatively POP is associated with problems regarding lubrication, dyspareunia and satisfaction [3-5]. Post hoc power analysis revealed that to have enough power $(\geq 0.8), 46$ patients are needed to evaluate sexual satisfaction, 181 for dyspareunia and 832 for lubrication.

\subsection{Secondary Outcome Measures}

Our quality of life analysis showed a significant improvement on the domain health change and a significant deterioration on the domain role functioning physical due to health problems. The latter focuses on limitations in work or daily activities. This deterioration can be explained by the short follow-up. The total score and the other domains didn't change significantly, although $73.9 \%$ of patients had an improvement in the total score. One patient with severe postoperative pain scored very low on all domains (total score 19.61), which is $\geq 2.5$ SD 
below the group average. In view of the small study population, it was thought that this outlier affected the scores of the entire group. This was confirmed when repeating the Wilcoxon signed rank test, omitting this patient. A significant improvement was found on the total score $(\mathrm{p}=0.049)$, vitality $(\mathrm{p}=0.025)$ and health change ( $<0.01)$. In all probability we can expect a significant improvement in quality of life with a larger study population, which would be supported by previous research $[8,19]$. As expected we found a significant improvement in cystocele $(\mathrm{p} \leq 0.001)$, rectocele $(\mathrm{p}=0.005)$ and descensus uteri $(\mathrm{p} \leq 0.001)$.

\subsection{In- and Exclusions}

As described under main findings, we excluded over a third of the patients because they were not sexually active, due to other reasons than POP. This finding was higher than expected since little is know about sexual activity. Over $20 \%$ of patients declined participation, of whom most found the subject of our study to burdened. Possibly there are more sexual problems in this specific group. This and the fact that two-thirds of women were sexually active, underlines the importance of this study.

\subsection{Strengths and Limitations}

Our study has several strengths. Our study population consisted of patients who solely underwent POP surgery, excluding patients with concomitant urinary-incontinence surgery $[3,8,9,11,15,16,18,19,21,22]$. We also excluded the possible bias of postoperative local estrogencreme $[7,10,13,14]$. To our knowledge this is the first study that took excluded patients into account and the specific reasons for being sexually inactive. In addition, we have taken patients who were not sexually active due to POP into analysis. For this group in particular it's interesting to know the influence of POP surgery on sexual functioning. Finally, our study had a high follow-up percentage (23 of 26 patients, 88.5\%), compared to the $50 \%$ $76 \%$ in other studies $[3,9,11,21,28]$.

Limitations of our study include the relative small study population, making it difficult to reach enough power to demonstrate significant differences. External factors, other than POP, might influence sexual functioning. Since we used a paired analysis, with every patient forming her own control, the role of external factors is expected to be low. With a short-term follow-up, we may assume the external factors to be equal pre- and postoperative in the majority of cases. Other limitations were lack of long-term follow-up and inclusion of different types of operations. Although we used a validated Dutch questionnaire, a recent study showed that the PISQ-IR is a validated and specific questionnaire to measure sexual function in women with pelvic floor dis- orders. [29] At the time of the design of our study, this study was not yet published.

\subsection{Interpretation}

Since post hoc power analysis showed that there was insufficient power to achieve statistic significance, a larger study is necessary before reliable conclusions can be drawn. However, for the outcome measure lubrication over 800 patients are needed.

\section{CONCLUSION}

More than a third of patients presenting with POP are not sexually active due to other reasons than POP. Our results show that POP surgery is successful with regard to anatomical correction. Concerning sexual function, surgery appears to improve lubrication, dyspareunia, sexual satisfaction and orgasm during intercourse in a considerable part of patients. Furthermore, there is no negative influence on sexual activity in women who were sexually active preoperatively. It even appears to improve sexual activity in women not sexually active preoperatively due to POP. POP surgery improves quality of life in the majority of patients.

\section{CONFLICT OF INTEREST}

All authors declare that they have no conflict of interest.

\section{ETHICAL APROVAL}

According to the Central Committee Human Bound Research (CCMO), no ethical approval is needed for research involving questionnaires. www.ccmo.nl.

\section{FUNDING}

Source of finance: none.

\section{REFERENCES}

[1] Hendrix, S.L., Clark, A., Nygaard, I., Aragaki, A., Barnabei, V. and Mc Tiernan, A. (2002) Pelvic organ prolapse in the Women's Health Initiative: Gravity and gravidity. American Journal of Obstetrics \& Gynecology, 186, 1160-1166. http://dx.doi.org/10.1067/mob.2002.123819

[2] Swift, S., Woodman, P., O’Boyle, A., Kahn, M., Valley, M. and Bland, D. (2005) Pelvic Organ Support Study (POSST): The distribution, clinical definition, and epidemiologic condition of pelvic organ support defects. American Journal of Obstetrics \& Gynecology, 192, 795-806. http://dx.doi.org/10.1016/j.ajog.2004.10.602

[3] Roovers, J.P., van der Bom, A., van Leeuwen, J.S., Scholten, P., Heintz, P. and van der Vaart, H. (2006) Effects of genital prolapse surgery on sexuality. Journal of Psychosomatic Obstetrics \& Gynecology, 27, 43-48. http://dx.doi.org/10.1080/01674820500245638 
[4] Athanasiou, S., Grigoriadis, T., Chalabalaki, A., Protopapas, A. and Antsaklis, A. (2012) Pelvic organ prolapse contributes to sexual dysfunction: A cross-sectional study. Acta Obstetricia et Gynecologica Scandinavica, 91, 704709. http://dx.doi.org/10.1111/j.1600-0412.2012.01396.x

[5] Thibault, F., Wagner, L., Rouvellat, P., Seni, G., Brouziyne, M. and de Tayrac, R. (2012) Sexual function before surgery for pelvic organ prolapse. Progrès en Urologie, 11, 665-670.

http://dx.doi.org/10.1016/j.purol.2012.08.266

[6] Weber, A.M., Walters, M.D., Schover, L.R. and Mitchinson, A. (1995) Vaginal anatomy and sexual function. $\mathrm{Ob}-$ stetrics \& Gynecology, 86, 946-949.

http://dx.doi.org/10.1016/0029-7844(95)00291-X

[7] Kuhn, A., Brunnmayr, G., Stadlmayr, W., Kuhn, P. and Mueller, M.D. (2009) Male and female sexual function after surgical repair of female organ prolapse. The Journal of Sexual Medicine, 6, 1324-1334. http://dx.doi.org/10.1111/j.1743-6109.2009.01229.x

[8] Caruso, S., Bandiera, S., Cavallaro, A., Cianci, S., Vitale, S.G. and Rugolo, S. (2010) Quality of life and sexual changes after double transobturator tension-free approach to treat severe cystocele. European Journal of Obstetrics \& Gynecology and Reproductive Biology, 151, 106-109. http://dx.doi.org/10.1016/j.ejogrb.2010.03.016

[9] Rogers, R.G., Kammerer-Doak, D., Darrow, A., Murray, K., Qualls, C. and Olsen, A. (2006) Does sexual function change after surgery for stress urinary incontinence and/ or pelvic organ prolapse? A multicenter prospective study. American Journal of Obstetrics \& Gynecology, 195, 1-4. http://dx.doi.org/10.1016/j.ajog.2006.09.021

[10] Hoda, M.R., Wagner, S., Greco, F., Heynemann, H. and Fornara, P. (2011) Prospective follow-up of female sexual function after vaginal surgery for pelvic organ prolapse using transobturator mesh implants. The Journal of Sexual Medicine, 3, 914-922.

http://dx.doi.org/10.1111/j.1743-6109.2010.01959.x

[11] Siddiqui, N.Y., Fulton, R.G., Kuchibhatla, M. and Wu, J.M. (2012) Sexual function after vaginal versus nonvaginal prolapse surgery. Female Pelvic Medicine \& Reconstructive Surgery, 18, 239-242. http://dx.doi.org/10.1097/SPV.0b013e31825ead35

[12] Dua, A., Jha, S., Farkas, A. and Radley, S. (2012) The effect of prolapse repair on sexual function in women. The Journal of Sexual Medicine, 9, 1459-1465. http://dx.doi.org/10.1111/j.1743-6109.2012.02660.x

[13] Vollebregt, A., Fischer, K., Gietelink, D. and van der Vaart, C.H. (2012) Effects of vaginal prolapse surgery on sexuality in women and men; results from a RCT on repair with and without mesh. The Journal of Sexual Medicine, 9, 1200-1211. http://dx.doi.org/10.1111/j.1743-6109.2011.02647.x

[14] Brandner, S., Monga, A., Mueller, M.D., Herrmann, G. and Kuhn, A. (2011) Sexual function after rectocele repair. The Journal of Sexual Medicine, 8, 583-588. http://dx.doi.org/10.1111/j.1743-6109.2010.02101.x

[15] Haase, P. and Skibsted, L. (1988) Influence of operations for stress incontinence and/or genital descensus on sexual life. Acta Obstetricia et Gynecologica Scandinavica, 67,
659-661. http://dx.doi.org/10.3109/00016348809004283

[16] Pauls, R.N., Silva, W.A., Rooney, C.M., Siddighi, S., Kleeman, S.D. and Dryfhout, V. (2007) Sexual function after vaginal surgery for pelvic organ prolapse and urinary incontinence. American Journal of Obstetrics \& Gynecology, 197, 622.e1-622.e7.

[17] Bartuzi, A., Futyma, K., Kulik-Rechberger, B., Skorupski, P. and Rechberger, T. (2012) Transvaginal Prolift ${ }^{\circledR}$ mesh surgery due to advanced pelvic organ prolapse does not impair female sexual function: A prospective study. European Journal of Obstetrics \& Gynecology and Reproductive Biology.

[18] Weber, A.M., Walters, M.D. and Piedmonte, M.R. (2000) Sexual function and vaginal anatomy in women before and after surgery for pelvic organ prolapse and urinary incontinence. American Journal of Obstetrics \& Gynecology, 182, 1610-1615. http://dx.doi.org/10.1067/mob.2000.107436

[19] Helstrom, L. and Nilsson, B. (2005) Impact of vaginal surgery on sexuality and quality of life in women with urinary incontinence or genital descensus. Acta Obstetricia et Gynecologica Scandinavica, 84, 79-84. http://dx.doi.org/10.1080/j.0001-6349.2005.00668.X

[20] Wang, C.L., Long, C.Y., Juan, Y.S., Liu, C.M. and Hsu, C.S. (2011) Impact of total vaginal mesh surgery for pelvic organ prolapse on female sexual function. International Journal of Gynecology \& Obstetrics, 115, 167-170. http://dx.doi.org/10.1016/j.ijgo.2011.05.019

[21] Long, C.Y., Juan, Y.S., Wu, M.P., Liu, C.M., Chiang, P.H. and Tsai, E.M. (2012) Changes in female sexual function following anterior with and without posterior vaginal mesh surgery for the treatment of pelvic organ prolapse. The Journal of Sexual Medicine, 9, 2167- 2174. http://dx.doi.org/10.1111/j.1743-6109.2012.02766.x

[22] Liang, C.C., Lo, T.S., Tseng, L.H., Lin, Y.H., Lin, Y.J. and Chang, S.D. (2012) Sexual function in women following transvaginal mesh procedures for the treatment of pelvic organ prolapse. International Urogynecology Journal, 23, 1455-1460.

[23] Elkadry, E.A., Kenton, K.S., FitzGerald, M.P., Shott, S. and Brubaker, L. (2003) Patient-selected goals: A new perspective on surgical outcome. American Journal of $\mathrm{Ob}$ stetrics \& Gynecology, 189, 1551-1558. http://dx.doi.org/10.1016/S0002-9378(03)00932-3

[24] Pieterse, Q.D., Ter Kuile, M.M., Maas, C.P. and Kenter, G.G. (2007) The Gynaecologic Leiden Questionnaire: psychometric properties of a selfreport questionnaire of sexual function and vaginal changes for gynaecological cancer patients. Department of Gynaecology, Leiden University Medical Centre, Leiden.

[25] Fashokun, T.B., Harvie, H.S., Schimpf, M.O., Olivera, C.K., Epstein, L.B., Jean-Michel, M., Rooney, K.E., Balgobin, S., Ibeanu, O.A., Gala, R.B. and Rogers, R.G. (2013) Sexual activity and function in women with and without pelvic floor disorders. Society of gynecologic surgeons' fellows' pelvic research network. International Urogynecology Journal, 24, 91-97. http://dx.doi.org/10.1007/s00192-012-1848-2

[26] Vervest, H.A.M. and van der Vaart, C.H. (2007) Bek- 
kenbodempathologie: Prolaps, urine-incontinentie en fecale incontinentie. In: Heineman, M.J., Evers, J.L.H., Massuger, L.F.A.G. and Steegers, E.A.P., Eds., Obstetrie en Gynaecologie, De Voortplanting van de Mens. 6th Edition, Elsevier, Maarssen, 731-758.

[27] Brölmann, H.A.M., Heineman, M.J. and Trimbos, J.B.M. Z. (2007) Operaties. In: Heineman, M.J., Evers, J.L.H., Steegers, E.A.P. and Steegers, E.A.P., Eds., Obstetrie en Gynaecologie. De Voortplanting van de Mens, 6th Edition, Elsevier, Maarssen, 873-907.
[28] Barber, M.D., Lambers, A., Visco, A.G. and Bump, R.C. (2000) Effect of patient position on clinical evaluation of pelvic organ prolapse. Obstetrics \& Gynecology, 96, 1822. http://dx.doi.org/10.1016/S0029-7844(00)00859-0

[29] Rogers, R.G., Rockwood, T.H. and Constantine, M.L. (2013) A new measure of sexual function in women with pelvic floor disorders (PFD): The Pelvic Organ Prolapse/ Incontinence Sexual Questionnaire, IUGA-Revised (PISQIR). International Urogynecology Journal, 24, 1091-1103. http://dx.doi.org/10.1007/s00192-012-2020-8 